\title{
PENGARUH LUAS PERMUKAAN BENDA TERHADAP KOEFISIEN GESEK STATIS DAN KINETIS PADA BIDANG MIRING DENGAN MENGGUNAKAN VIDEO TRACKER
}

\author{
D. Amirudin ${ }^{1, \text { a) }}$, R. B. Astro ${ }^{1)}$, D.H. Mufida ${ }^{1)}$, S. Humairo ${ }^{1)}$, S. Viridi ${ }^{2)}$ \\ ${ }^{1}$ Program Studi Magister Pengajaran Fisika, Fakultas Matematika dan Ilmu Pengetahuan Alam Institut \\ Teknologi Bandung \\ Jl. Ganesha no. 10 Bandung, Indonesia, 401322 \\ ${ }^{2}$ Laboratorium Fisika Nuklir, Kelompok Keilmuan Fisika Nuklir dan Biofisika, Fakultas Matematika dan Ilmu \\ Pengetahuan Alam, Institut Teknologi Bandung Jl. Ganesha no. 10 Bandung, Indonesia, 40132 \\ E-mail: a) Amirudin.dessy@gmail.com
}

\begin{abstract}
Abstrak
Penelitian ini merupakan lanjutan dari penelitian sebelumnya tentang analisis koefisien gesek statis dan kinetis benda di bidang miring dengan menggunakan video tracker. Tujuan penelitian ini adalah menentukan pengaruh luas permukaan benda terhadap koefisien gesek statis dan kinetis. Alat yang digunakan adalah sebuah landasan kayu dan benda berbahan aluminium. Rangka dasar benda dibuat persegi, sedangkan design permukaan benda dibuat berbeda. Tiap sisi permukaan didesign memenuhi bangun datar dengan masing-masing permukaan berbentuk persegi, persegi panjang, segitiga, trapesium dan lingkaran. Eksperimen diujikan pada suatu sistem bidang dengan kemiringan yang dapat diatur sesuai dengan kebutuhan. Untuk menentukan koefisien gesek statis, eksperimen dilakukan dengan mencari sudut kemiringan landasan saat benda tepat akan bergerak. Sedangkan koefisien gesek kinetis dapat ditentukan dengan mengamati luncuran benda dari puncak bidang miring yang telah diatur sudutnya. Benda diletakan pada landasan bidang dengan pengaturan sudut untuk koefisen gesek kinetis dan tanpa pengaturan sudut untuk koefisien gesek statis pada landasan. Eksperimen ini didokumentasikan untuk selanjutnya dianalisis menggunakan video tracker. Hasil yang diperoleh adalah bahwa luas permukaan benda berpengaruh terhadap koefisien gesek statis dan kinetis.
\end{abstract}

Keywords: koefisien gesek statis dan kinetis, luas permukaan, video tracker

\begin{abstract}
This research is a continuation of previous research on static friction coefficient analysis and objects kinetic in the sloping field using video tracker. The purpose of this study is to determine the effect of the relation of the surface area of the object to the static and kinetic friction coefficient. The tool used is a wooden platform and objects made from aluminum. The basic frame of the object is made square, while the design of the object surface is made differently. Each side of the surface in the design fills the flat with each square, rectangular, triangular, trapezoidal and circular surface. Experiments were tested on a plane system with an adjustable slope as needed. To determine the static friction coefficient, the experiment is performed by looking for the angle of the runway when the right object moves. While the kinetic friction coefficient can be determined by observing the slide of the object from the top of the sloped angle of the inclined plane. The object is placed on the ground plane by the staggered arrangement for the kinetic friction coefficient and without the angular arrangement for the static friction coefficient on the runway. This experiment is documented for subsequent analysis using a video
\end{abstract}


tracker. The results obtained are that the surface area of the object affects the coefficient of static and kinetic friction

Keywords: friction coefficient of static and kinetic, surface area, a video tracker

\section{PENDAHULUAN}

Suatu benda yang bersinggungan dan kemuadian diamati, maka akan terlihat bahwa pergerakanya seperti dilawan oleh suatu gaya. Fenomena ini dinamakan gesekan. Sedangkan gaya yang bekerja didalamnya disebut dengan gaya gesek[1]. Benda diam cenderung memiliki gaya gesek statis yang berlawanan dengan arah geraknya. Ketika benda yang berada diatas landasan diberi gaya yang sejajar dan tidak bergerak, maka gaya gesek bernilai lebih besar dari nol hingga mencapai nilai gaya gesek statis maksimum[2]. Gaya gerak yang lebih besar dari gaya gesek statis maksimum akan membuat benda bergerak, dengan demikian gaya-gaya gesek yang bekerja akan berkurang besarnya, sehingga untuk mempertahankan gerak dibutuhkan gaya yang lebih kecil yakni gaya gesek kinetis[3]. Perbandingan gaya gesek kinetis maupun statis maksimum dengan gaya normalnya masing-masing dikenal dengan nama koefisien gesek kinetis dan statis. Nilai-nilai ini bergantung pada banyak variabel seperti sifat material, suhu, lapisan permukaan dan pengotoran[4]. Beberapa variabel seperti suhu, sifat material dan lapisan permukaan sangat erat kaitanya dengan permukaan bidang kontak yang mengalami gesekan. Dengan demikian seharusnya luas permukaan bidang berpengaruh terhadap besarnya koefisien gesek. Namun ternyata teori dalam tinjauan literatur tidak menyatakan demikian. Dalam fisika untuk membuktikan kebenaran suatu teori dibutuhkanlah eksperimen. Salah satu metode yang digunakan untuk membuktikan masalah ini adalah dengan menggunakan video tracker. Tracker adalah Software khusus yang dibuat untuk melacak pergerakan objek seperti menghasilkan parameter posisi, kecepatan, percepatan, energi kinetik, momentum dan lain sebagainya. Sehingga setiap parameter gerak dapat dianalisis dengan lebih teliti [5].

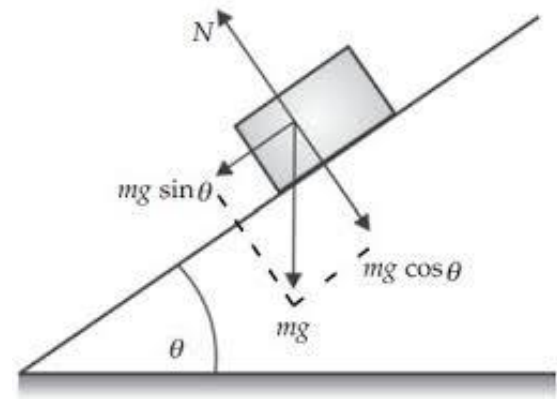

TINJAUAN PUSTAKA

GAMBAR 1. Diagram gaya

\section{Koefisien gesek statis $\left(\mu_{\mathrm{s}}\right)$}

Benda diletakkan pada sebuah bidang dengan kemiringan seperti GAMBAR 1 dalam keadaan diam. Dalam posisi ini gaya gesek statis yang bekerja pada benda sebanding dengan komponen gaya berat benda pada arah $x$. Jika sudut kemiringan bidang diubah sebesar $\theta^{0}$ maka benda tepat akan bergerak, sehingga gaya gesek statis antara permukaan benda dan bidang mencapai nilai maksimum. Perbandingan antara gaya gesek statis dengan gaya normalnya adalah koefisien gesek statis $\left(\mu_{\mathrm{s}}\right)$.

$$
\vec{f}_{\mathrm{s} \max }=\mu_{s} \vec{N}
$$


$\vec{N}$ adalah gaya normal yang diberikan permukaan bidang pada benda. Karena benda tidak bergerak pada arah $y$, maka berdasarkan hukum I Newton, diperoleh:

$$
\begin{gathered}
\sum F_{y}=0 \\
N=m g \cos \theta
\end{gathered}
$$

Komponen gaya pada arah $x$ dapat dijabarkan sebagai berikut:

$$
\begin{gathered}
\sum F_{x}=0 \\
m g \sin \theta-f_{s}=0 \\
m g \sin \theta=\mu_{s} N \\
m g \sin \theta=\mu_{s} m g \cos \theta
\end{gathered}
$$

Dengan demikian, diperoleh persamaan untuk menentukan koefisien gesek statis $\left(\mu_{\mathrm{s}}\right)$ yakni [3]:

$$
\mu_{s}=\tan \theta
$$

\section{Koefisien Gesek Kinetis}

Suatu benda diletakkan pada suatu bidang dengan sudut kemiringan tertentu dalam keadaan diam dan kemudian meluncur dengan percepatan sebesar $a$, maka gaya gesek antara permukaan benda dan bidang adalah gaya gesek kinetis. Perbandingan antara gaya gesek kinetis dengan gaya normal mempunyai nilai yang relatif konstan disebut dengan koefisien gesek kinetis $\left(\mu_{\mathrm{k}}\right)$.

Komponen gaya pada arah $x$ dapat dijabarkan sebagai berikut:

$$
\begin{gathered}
\sum F_{x}=m a \\
m g \sin \theta-f_{k}=m a \\
m g \sin \theta-\mu_{k} m g \cos \theta=m a \\
g\left(\sin \theta-\mu_{k} \cos \theta\right)=a
\end{gathered}
$$

Bila $a$ adalah $d v / d t$ maka kecepatan (v) didapatkan dari hasil integral dari persamaan

$$
\begin{gathered}
\int d v=\int g\left(\sin \theta-\mu_{k} \cos \theta\right) d t \\
v=\left(\sin \theta-\mu_{k} \cos \theta\right) g t+v_{0}
\end{gathered}
$$

Persamaan (5) dapat didekati dengan regresi linear grafik kecepatan benda tiap satuan waktu, dengan gradien kemiringan $A$.

$$
\begin{gathered}
v=A t+B \\
A=\left(\sin \theta-\mu_{k} \cos \theta\right) g
\end{gathered}
$$

Dengan demikian, diperoleh persamaan untuk menentukan koefisien gesek kinetis $\left(\mu_{\mathrm{k}}\right)$ yakni [3]:

$$
\mu_{k}=\tan \theta-\frac{A}{g \cos \theta}
$$




\section{METODE PENELITIAN}

Tujuan penelitian adalah untuk mengetahui pengaruh luas permukaan benda terhadap koefisien gesek statis $\left(\mu_{s}\right)$ dan kinetis $\left(\mu_{k}\right)$.

\section{Alat dan bahan}

1. Sitem terdiri dari satu set kotak portable berukuran $8 \mathrm{~cm} \times 15 \mathrm{~cm} \times 30 \mathrm{~cm}$ dengan landasan permukaan sepanjang $20 \mathrm{~cm}$, lengkap dengan busur derajat;

2. Benda berbahan aluminium didesign khusus dengan ukuran $3 \mathrm{~cm} \times 3 \mathrm{~cm} \times 3 \mathrm{~cm}$, yang massa dibuat konstan (45 gr);

3. Luas permukaan dibuat bervariasi, yakni persegi, persegi panjang, trapesium, lingkaran dan segitiga;

4. Kamera DSL Canon EOS;

5. Aplikasi software tracker video Analysis and Modeling Tool (Ver 4.11.0)

Detail set up eksperimen dan skema luas permukaan benda masing-masing disajikan oleh GAMBAR 2 dan GAMBAR 3.

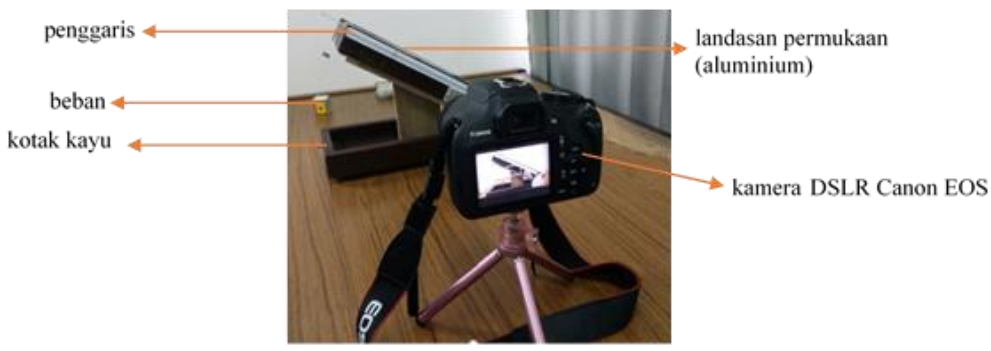

GAMBAR 2. Set up sistem

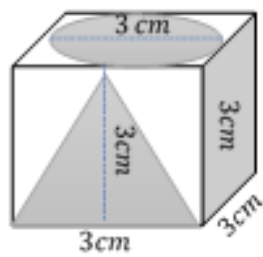

GAMBAR 3. Skema luas permukaan beban

\section{PROSEDUR}

Langkah awal sebelum dimulaianya eksperimen adalah merangkai sistem seperti pada GAMBAR 2. Kedua data yakni koefisen gesek statis $\left(\mu_{s}\right)$ dan koefisien gesek kinetik $\left(\mu_{k}\right)$ diambil dengan perlakukan berbeda.

\section{Menentukan Koefisen Gesek Statis $\left(\mu_{s}\right)$}

Benda diletakan pada landasan dengan kemiringan $0^{\circ}$; kemudian kemiringan diubah perlahan hingga benda tepat akan bergerak; eksperimen dilakukan berulang sehingga diperoleh lima data. Proses pergerakan direkam menggunakan kamera DSLR Canon EOS. Data yang telah direkam kemudian dianalisis dengan menggunakan software tracker.

\section{Koefisen gesek kinetis $\left(\mu_{k}\right)$}

Benda diletakan pada kemiringan $\theta^{\circ}$; eksperimen dilakukan berulang hingga diperoleh dua data dari besar kemiringan yang sama. Kemudian memvariasi sudut kemiringan sebanyak empat kali. 
Eksperimen dilakukan dengan mengganti luas permuakaan beban. Selanjutnya merekam pergerakan benda dengan menggunakan kamera DSLR Canon EOS. Data yang telah terekam kemudian dianalisis dengan menggunakan video tracker seperti pada GAMBAR 4.

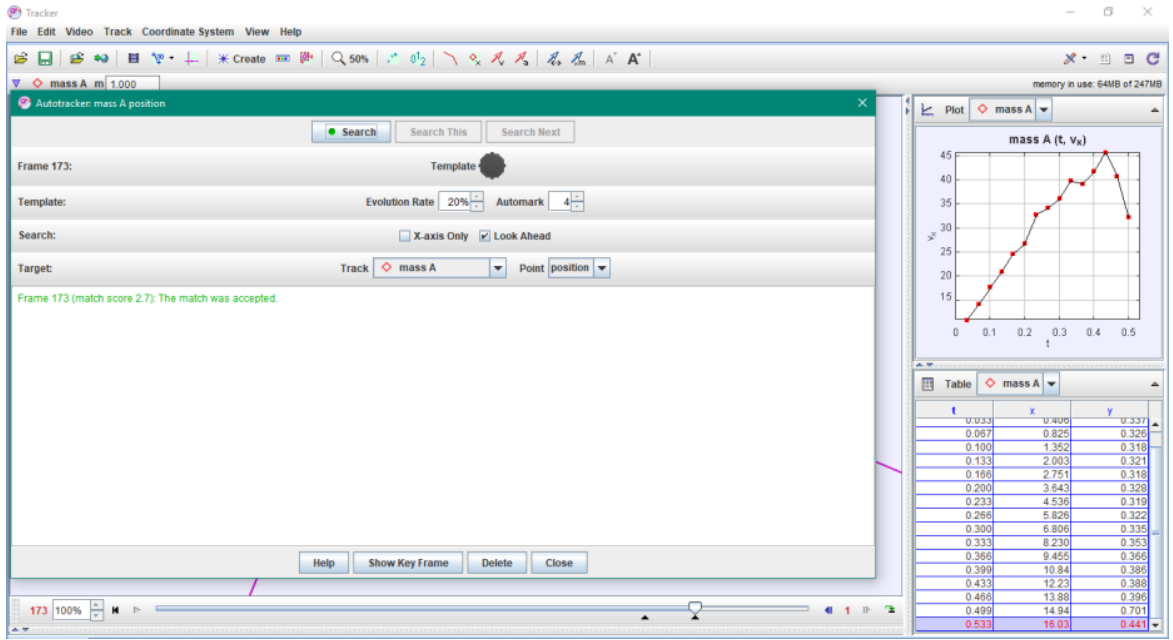

GAMBAR 4. Proses analisis data

\section{HASIL DAN PEMBAHASAN}

Pengambilan data dilaksanankan di Labolatorium Basic Science Center A (BSCA-ITB). Suhu dan kelembaban ruangan dimanipulasi sedemikian rupa untuk menghindari faktor-faktor luar yang menyebabkan kacaunya gesekan antara bidang miring dan permukaan beban.

\section{Koefisien gesek statis}

Berdasarkan hasil analisis melalui video tracker didapatkan hasil koefisien gesek statis $\left(\mu_{s}\right)$ pada masing-masing luas permukaan sebagai berikut :

TABEL 1. Nilai koefisen gesek statis $\left(\mu_{s}\right)$

\begin{tabular}{lcc}
\hline & $\begin{array}{c}\text { Luas Permukaan } \\
(\boldsymbol{c m})\end{array}$ & $\boldsymbol{\mu s}(\tan \boldsymbol{\theta})$ \\
\hline Lingkaran & 7.065 & 0.461 \\
Persegi & 9 & 0.445 \\
Persegi panjang & 4.5 & 0.430 \\
Segitiga & 3.45 & 0.451 \\
Trapesium & 5.7 & 0.424 \\
\hline
\end{tabular}

TABEL 1 menyatakan bahwa nilai koefisien gesek statis $\left(\mu_{s}\right)$ pada masing-masing luas permukaan hampir sama, artinya tidak ada perbedaan yang signifikan, perbedaan interval nilai koefisien gesek statis satu dengan yang lainya adalah \pm 0.037 . Nilai korelasi kedua variabel adalah 0.78 . Hal ini berarti luas permukaan berpengaruh terhadap koefisien gesek statis.

\section{Koefisien gesek kinetis}

Data pada eksperimen ini dilakukan pada empat sudut yang berbeda, dengan masing-masing perulangan sebanyak dua kali. Kemudian data yang telah diperoleh dianalisis dengan menggunakan software tracker. Proses tracking berfungsi untuk menentukan posisi benda per frame, kecepatan benda, serta menampilkan grafik kecepatan $(v)$ terhadap waktu $(t)$ seperti pada GAMBAR 5. 


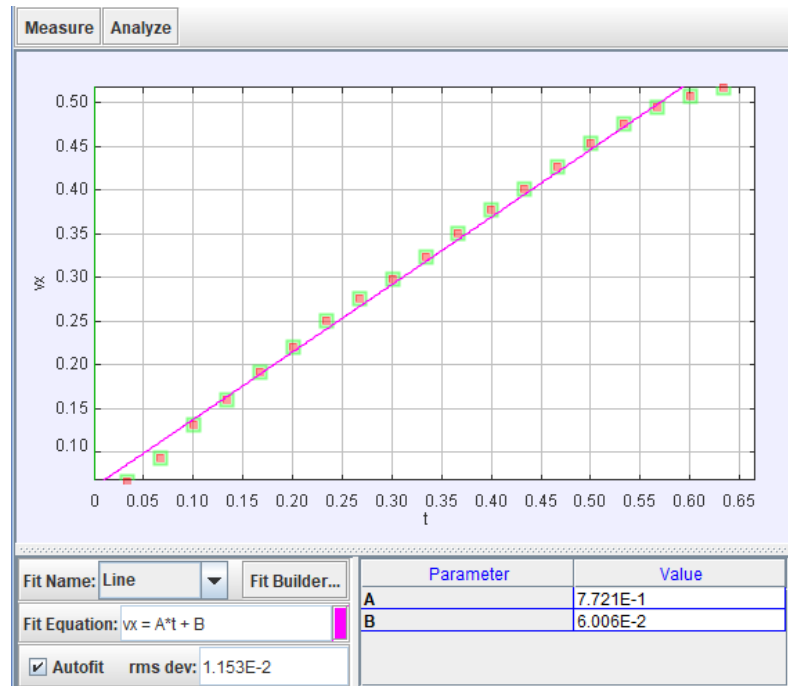

GAMBAR 5. Parameter A dan B

TABEL 2. Koefisien gesek kinetis $\left(\mu_{s}\right)$

\begin{tabular}{cccccc}
\hline \multirow{2}{*}{$\begin{array}{c}\text { Sudut } \\
\left(\theta^{\circ}\right)\end{array}$} & \multicolumn{5}{c}{ Luas Permukaan Beban } \\
\cline { 2 - 6 } & Lingkaran & Segitiga & Persegi & Persegi Panjang & Trapesium \\
\hline 26 & 0.376 & 0.319 & 0.374 & 0.345 & 0.327 \\
28 & 0.381 & 0.359 & 0.387 & 0.384 & 0.35 \\
30 & 0.405 & 0.39 & 0.472 & 0.4 & 0.378 \\
32 & 0.432 & 0.431 & 0.444 & 0.488 & 0.426 \\
\hline
\end{tabular}

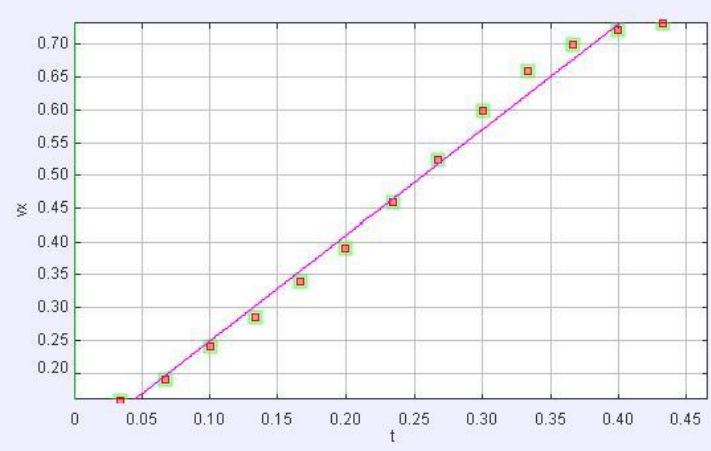

(a)

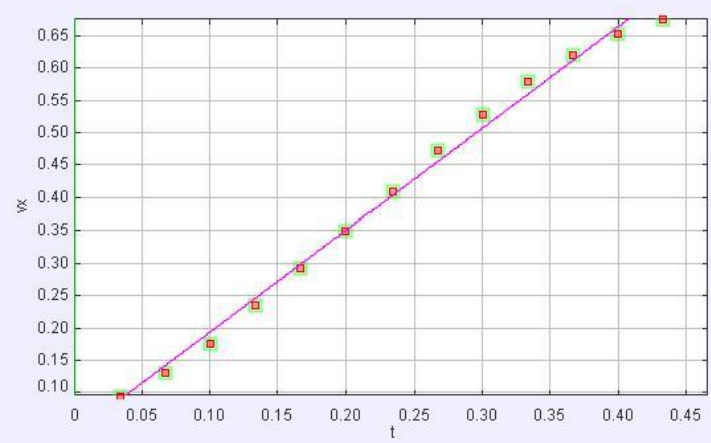

(c)

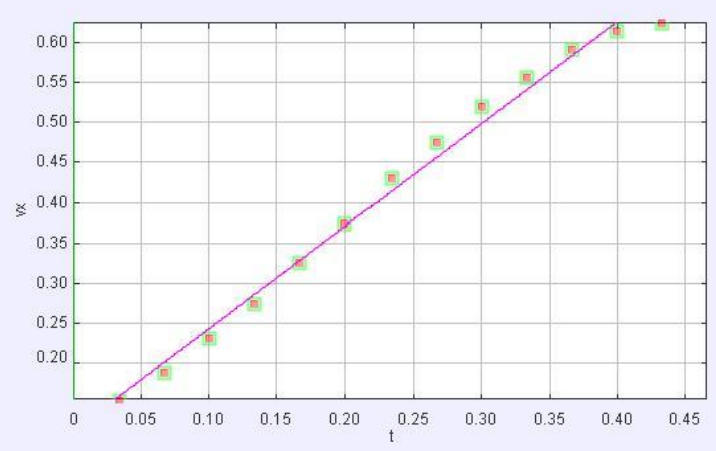

(b)

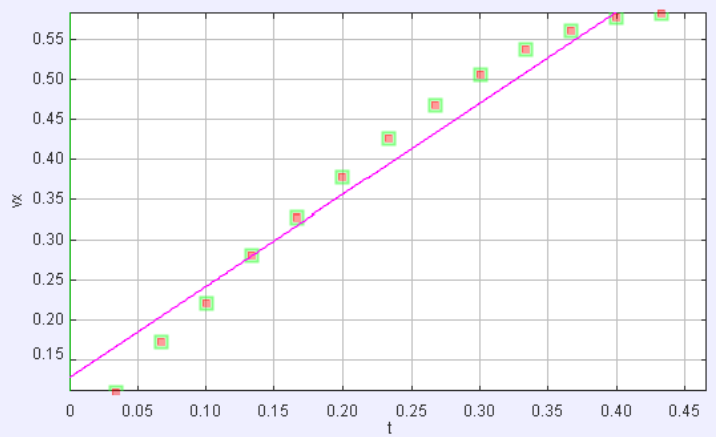

(d)

GAMBAR 6. Grafik regresi kecepatan terhadap $v(t)$ waktu pada luas permukaan (a) lingkaran $32^{\circ}$, (b) persegi $32^{\circ}$, (c) trapesium $28^{\circ}$, (d) persegi panjang $28^{\circ}$ 
Nilai koefisen gesek kinetis didapatkan dengan menggunakan regresi linear grafik pada persamaan (8). Hasil koefisen gesek kinetik yang telah dianalisis disajikan pada TABEL 2. TABEL 2 menunjukan bahwa nilai koefisien gesek kinetis $\left(\mu_{k}\right)$ satu dengan yang lainya memiliki perbedaan yang tidak signifikan, besarnya hanya \pm 0.169 . Nilai $r$ hitung product moment pada masing-masing koefisien gesek kinetik lebih besar daripada nilai $r$ tabel. Hal ini mengindikasikan bahwa luas permukaan berpengaruh terhadap koefisien gesek kinetik.

Pada GAMBAR 6, masing-masing grafik kecepatan terhadap waktu tampak tidak linear. Hal ini terjadi karena adanya percepatan yang dialami benda, namun besar percepatan tidaklah signifikan atau relatif kecil.

\section{SIMPULAN}

Berdasarkan eksperimen yang telah dilakukan, dapat disimpulkan bahwa luas permukaan berpengaruh terhadap koefisien gesek statis $\left(\mu_{s}\right)$ dan kinetis $\left(\mu_{k}\right)$.

\section{UCAPAN TERIMKASIH}

Penulis mengucapkan terimkasih kepada semua pihak yang telah membantu dalam menyelesaikan penelitian ini.

\section{REFERENSI}

[1] V. Spirisoma, Modul Fisika Dasar. Bandung: ITB Press, 2010.

[2] S. Humairo, et al., "Analisis koefisien gesek statis dan kinetis berbagai pasangan permukaan bahan pada bidang miring menggunakan aplikasi analisis video tracker",dalam Seminar Nasional Quantum \#25., 2018, pp. 2477-1511.

[3] Priyono. J., "Penenerapan metode video tracking pada pengukuran koefisien gesek kinetis luncuran", dalam Pros. Pertemuan Ilmiah XXVIII., 2018, pp. 50-53.

[4] Satriawan Mirza. 2007, Modul Fisika Dasar. Yogyakarta: UGM, 2012.

[5] Douglas Brown dan Wolfgang Christian, "Tracker". 2012 di unduh dari http://www.opensourcephysics.org 